\title{
Comparison of lead zirconate titanate thin films on ruthenium oxide and platinum electrodes
}

L. A. Bursill, Ian M. Reaney, D. P. Vijay, and S. B. Desu

Citation: Journal of Applied Physics 75, 1521 (1994); doi: 10.1063/1.356388

View online: http://dx.doi.org/10.1063/1.356388

View Table of Contents: http://scitation.aip.org/content/aip/journal/jap/75/3?ver=pdfcov

Published by the AIP Publishing

\section{Articles you may be interested in}

Effects of chemical stability of platinum/lead zirconate titanate and iridium oxide/lead zirconate titanate interfaces on ferroelectric thin film switching reliability

Appl. Phys. Lett. 91, 232906 (2007); 10.1063/1.2822419

Comparison of the agglomeration behavior of thin metallic films on Si O 2

J. Vac. Sci. Technol. A 23, 1152 (2005); 10.1116/1.1861943

Effects of the top-electrode size on the piezoelectric properties ( $d 33$ and S ) of lead zirconate titanate thin films

J. Appl. Phys. 96, 2800 (2004); 10.1063/1.1775306

Dielectric loss peak due to platinum electrode porosity in lead zirconate titanate thin-film capacitors Appl. Phys. Lett. 81, 2436 (2002); 10.1063/1.1509855

Schottky barrier effects in the electronic conduction of sol-gel derived lead zirconate titanate thin film capacitors

J. Appl. Phys. 84, 5005 (1998); 10.1063/1.368747

\section{MIT LINCOLN}

LABORATORY CAREERS

Discover the satisfaction of innovation and service

to the nation
- Space Control

- Air \& Missile Defense

- Communications Systems \& Cyber Security

- Intelligence, Surveillance and Reconnaissance Systems

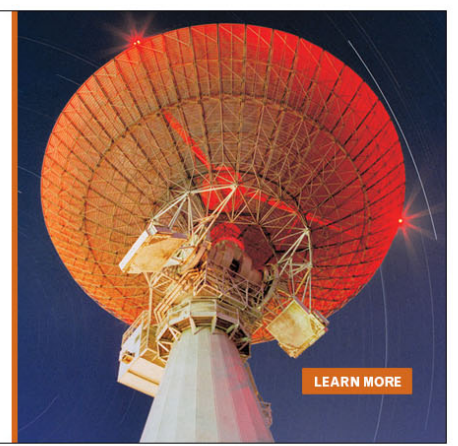




\title{
Comparison of lead zirconate titanate thin films on ruthenium oxide and platinum electrodes
}

\author{
L. A. Bursill ${ }^{a)}$ and lan M. Reaney \\ Laboratoire de Ceramique, MX-D, Ecole Polytechnique Federale de Lausanne, Ecublens, CH-1015, \\ Switzerland \\ D. P. Vijay and S. B. Desu \\ Department of Materials Science and Engineering, Virginia Polytechnic Institute and State University, \\ Blacksburg, Virginia 24061
}

(Received 23 July 1993; accepted for publication 17 October 1993)

\begin{abstract}
High-resolution and bright- and dark-field transmission electron microscopy are used to characterize and compare the interface structures and microstructure of $\mathrm{PZT} / \mathrm{RuO}_{2} / \mathrm{SiO}_{2} / \mathrm{Si}$ and $\mathrm{PZT} / \mathrm{Pt} / \mathrm{Ti} / \mathrm{SiO}_{2} / \mathrm{Si}$ ferroelectric thin films, with a view to understanding the improved fatigue characteristics of PZT thin films with $\mathrm{RuO}_{2}$ electrodes. The $\mathrm{RuO}_{2} / \mathrm{PZT}$ interface consists of a curved pseudoperiodic minimal surface. The interface is chemically sharp with virtually no intermixing of $\mathrm{RuO}_{2}$ and PZT, as evidenced by the atomic resolution images as well as energy dispersive $\mathrm{x}$-ray analysis. A nanocrystalline pyrochlore phase $\mathrm{Pb}_{2} \mathrm{ZrTiO}_{7-x}, x \neq 1$, was found on the top surface of the PZT layer. The $\mathrm{PZT} / \mathrm{Pt} / \mathrm{Ti} / \mathrm{SiO}_{2} / \mathrm{Si}$ thin film was well crystallized and showed sharp interfaces throughout. Possible reasons for the improved fatigue characteristics of $\mathrm{PZT} / \mathrm{RuO}_{2} / \mathrm{SiO}_{2} / \mathrm{Si}$ thin films are discussed.
\end{abstract}

\section{INTRODUCTION}

Interface-related degradation problems of ferroelectric $\mathrm{PbZr}_{0.53} \mathrm{Ti}_{0.47} \mathrm{O}_{3}$ thin film switching characteristics led to the search for alternate electrode materials to replace the conventional platinum electrodes. The suitability of the ceramic conducting electrodes ruthenium dioxide $\left(\mathrm{RuO}_{2}\right)$ and indium-tin-oxide (ITO) was examined by Vijay and Desu. ${ }^{1}$ Thin films of $\mathrm{RuO}_{2}$ and ITO were deposited onto $\mathrm{Si} / \mathrm{SiO}_{2}$ substrates by reactive sputtering. Sol-gel derived PZT thin films were deposited onto the conducting electrodes and the samples annealed at various temperatures between 400 and $700^{\circ} \mathrm{C}$. Less intermixing was observed for the $\mathrm{Si} / \mathrm{SiO}_{2} / \mathrm{RuO}_{2} / \mathrm{PZT}$ films than for $\mathrm{Si} / \mathrm{SiO}_{2} / \mathrm{ITO} / \mathrm{PZT}$ after similar PZT processing. The ferroelectric properties of the PZT films, i.e., hysteresis, fatigue, and low voltage breakdown, were also compared for the two sets of electrodes. Improved fatigue properties were observed for the $\mathrm{RuO}_{2}$ electrodes. The latter also showed better currentvoltage $(I-V)$ and time-dependent dielectric breakdown properties. Earlier studies of $\mathrm{RuO}_{2}$ electodes on PZT were reported by $\mathrm{Yoo}$ and $\mathrm{Desu}^{2,3}$ and Vijay et al. ${ }^{4} \mathrm{RuO}_{2}$ is more readily etched than is $\mathrm{Pt}$, which is interesting for potential very large scale integration of PZT thin films.

The purpose of the present paper is to compare the $\mathrm{PZT} /$ electrode interface structures for $\mathrm{RuO}_{2}$ and $\mathrm{Pt}$ electrodes, with respect to understanding the different degradation properties for $\mathrm{Pt}$ and $\mathrm{RuO}_{2}$. According to a theoretical model for degradation of oxide ferroelectrics due to Desu and Yoo, ${ }^{5}$ the structure of the PZT/electrode is assumed to have the major effect on the degradation properties, i.e., on fatigue, aging, and $I-V$ characteristics, of a ferroelectric capacitor. That model assumed that oxygen-

\footnotetext{
a) Permanent address: School of Physics, The University of Melbourne, Parkville Vic., 3052, Australia.
}

vacancy migration and trapping at the PZT/electrode interface is responsible for loss of switchable polarization after repeated switching (fatigue). Experiments showed that $\mathrm{RuO}_{2}$ electrodes gave much reduced fatigue, compared to $\mathrm{Pt},{ }^{1}$ which was attributed to increased stability of the $\mathrm{RuO}_{2} / \mathrm{PZT}$ interface resulting from reduced lattice mismatch, a more favorable contact potential, and a sharp interface structure, with virtually no interdiffusion of $\mathrm{PZT} / \mathrm{RuO}_{2}$.

It was proposed that such increased stability reduces any tendency for oxygen-vacancy migration and subsequent trapping at the interface. Vijay and Desu ${ }^{1}$ suggested that the composition gradient is reduced for $\mathrm{PZT} / \mathrm{RuO}_{2}$ by formation of a thin layer of a $\mathrm{Pb}_{2} \mathrm{Ru}_{2} \mathrm{O}_{7-x}$ pyrochlore phase at the interface due to a limited extent of chemical mixing during the $650^{\circ} \mathrm{C}, 30 \mathrm{~min}$ annealing required to crystallize the PZT.

The original aim of the present paper was to attempt to detect this compound using high-resolution transmission electron microscopy (HRTEM); it was also interesting to compare, as directly as possible, the interface structures of $\mathrm{PZT} / \mathrm{Pt}$ and PZT/RuO ${ }_{2}$ capacitors. The results of HRTEM, as well as classical bright- and dark-field TEM and some analytical electron microscopy are reported below.

\section{EXPERIMENT}

\section{A. Fabrication details}

Bare Si(100) wafers were first oxidized in an atmosphere of wet oxygen at $950^{\circ} \mathrm{C}$ to form the amorphous $\mathrm{SiO}_{2}$ barrier layers. This is to prevent contact between $\mathrm{Pt}$ and $\mathrm{Si}$, which would otherwise form complex platinum silicides. ${ }^{6}$ An additional thin Ti layer was sputtered onto the silica to improve adhesion of $\mathrm{Pt}$ to the silica substrate. ${ }^{7}$ This was not necessary for $\mathrm{RuO}_{2}$ on silica. 
$\mathrm{Si} / \mathrm{SiO}_{2} / \mathrm{RuO}_{2} / \mathrm{PZT}$

$\mathrm{PbZr}_{x} \mathrm{Ti}_{1-z} \mathrm{O}_{3}, \mathrm{x}=0.53400 \mathrm{~nm}$ thin film $\mathrm{RuO}_{2}$ bottom electrode $250 \mathrm{~nm}$ $\mathrm{SiO}_{2}$ barrier layer $100 \mathrm{~nm}$ Si substrate

\section{$\mathrm{Si} / \mathrm{SiO}_{2} / \mathrm{Ti} / \mathrm{Pt} / \mathrm{PZT}$}

$\mathrm{PbZr}_{x} \mathrm{Ti}_{1-x} \mathrm{O}_{3}, \mathrm{x}=0.53400 \mathrm{~nm}$ thin film Pt bottom electrode $300 \mathrm{~nm}$

Ti adhesion layer 30nm

$\mathrm{SiO}_{2}$ barrier layer $200 \mathrm{~nm}$

Si substrate

FIG. 1. Comparison of chemical and dimensional specifications of the two PZT thin films studied herein.

$\mathrm{RuO}_{2}$ electrodes were sputtered reactively onto the $\mathrm{Si} / \mathrm{SiO}_{2}$ substrate using a ruthenium metal target in an atmosphere of oxygen/argon in the ratio-1:4; the gas pressure was 10 mTorr during sputtering with a current of 0.2 A. The $\mathrm{Pt}$ electrode was also deposited onto the $\mathrm{Si} / \mathrm{SiO}_{2} / \mathrm{Ti}$ substrate using a dc magnetron sputterer in an atmosphere of argon.

The $\mathrm{PbZr}_{x} \mathrm{Ti}_{1-x} \mathrm{O}_{3}, x=0.53$ precursor solution was prepared by a sol-gel technique from a metalorganic solution of $\mathrm{Zr}$-iso-propoxide, Ti-n-propoxide and $\mathrm{Pb}$-acetate. $10 \%$ excess $\mathrm{Pb}$ was added to the solution to compensate for the expected loss of lead during crystallization of the PZT at $650^{\circ} \mathrm{C}$. The solution was hydrolyzed to form the precursor with a concentration of $0.4 \mathrm{M}$. PZT thin films were spin coated onto the electrodes; with adjustment of the number of coatings and speed of coating to obtain the desired thickness of $400 \mathrm{~nm}$. The coated films were dried in air.

These as-deposited films were amorphous. PZT was crystallized by annealing at $6500^{\circ} \mathrm{C}$ for $30 \mathrm{~min}$ a quartz tube furnace, in air. Figure 1 shows chemical details as well as dimensional specifications of the two thin films studied herein.

\section{B. Electron microscopy}

Four pieces, each $3 \mathrm{~mm}^{2}$, were cleaved from the two PZT/electrode specimens. These were glued together using an epoxy resin as a stack with two pairs of PZT surfaces facing inward. These sandwiches were ground mechanically using fine-grade silicon carbide paper in such a way as to produce transverse cross sections $30 \mu \mathrm{m}$ deep. A $2.3 \mathrm{~mm}$ copper specimen support ring was glued to one surface and the sample ion thinned from both sides at an angle of incidence of $15^{\circ}$. This is a modification of a technique developed for ferroelectric thin films by Reaney and Barber; ${ }^{8}$ see also Sreenivas et al. ${ }^{9}$

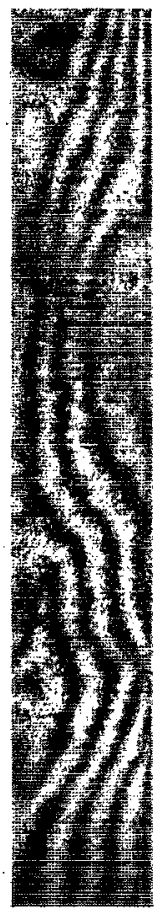

Si

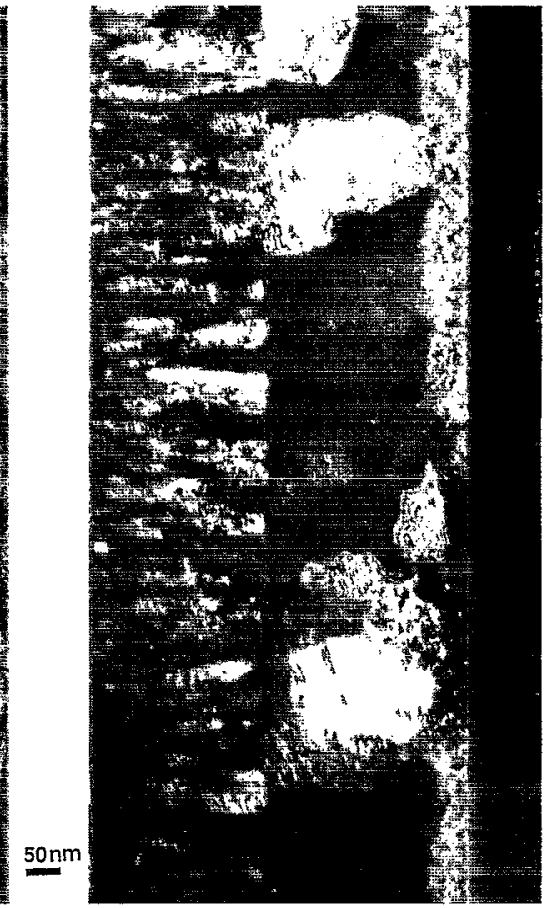

$\mathrm{SiO}_{2}$

$\mathrm{RuO}_{2}$

PZT

Epoxy

FIG. 2. Overview of $\mathrm{PZT} / \mathrm{RuO}_{2} / \mathrm{SiO}_{2} / \mathrm{Si}$ thin film showing the interface structures and the texture of the $\mathrm{RuO}_{2}$ and PZT layers.

The thin specimens were examined using a Philips EM430 $300 \mathrm{keV}$ HRTEM instrument at Institut Interdepartmentale de Microscopie Electronique (I2M), EPFL. Observations were made at close to room temperature using a $\pm 10^{\circ}$ double-tilt goniometer. The instrumental resolution was significantly better than $0.2 \mathrm{~nm}$ although the interpretable structure resolution was limited to $0.2 \mathrm{~nm}$, since the spherical aberation coefficient was $1.2 \mathrm{~mm}$. Selected area diffaction patterns were recorded using the smallest projector lens aperture, when the effective beam diameter at the specimen plane was about $100 \mathrm{~nm}$.

Some energy dispersive $x$-ray spectroscopy (EDX) analysis was made using a Hitachi 2000-HF fleld-emission analytical electron microscope at $200 \mathrm{keV}$, also at I2M.

\section{RESULTS}

\section{A. $\mathrm{PZT} / \mathrm{RuO}_{2} / \mathrm{SiO}_{2} / \mathrm{Si}$}

Figure 2 shows an overall view of one thin film cross section; from left to right may be seen crystalline $\mathrm{Si}$ /amorphous $\mathrm{SiO}_{2}$ /columnar crystallites of $\mathrm{RuO}_{2}$ / crystallized PZT/ and amorphous epoxy. This is a darkfield image with objective aperture centered over the polycrystalline electron diffraction ring pattern (Fig. 3). The PZT portion consists of grains some $25 \mathrm{~nm}$ diam. The $\mathrm{RuO}_{2}$ layer is well crystallized, indicated by extensive arrays of lattice fringes; shown in the enlargement of Fig. 2 given as Fig. 4. It has a pronounced columnar texture, where each grain (about $5 \mathrm{~nm}$ wide) extends throughout the thickness of the $\mathrm{RuO}_{2}$ layer (about $250 \mathrm{~nm}$ thick). 


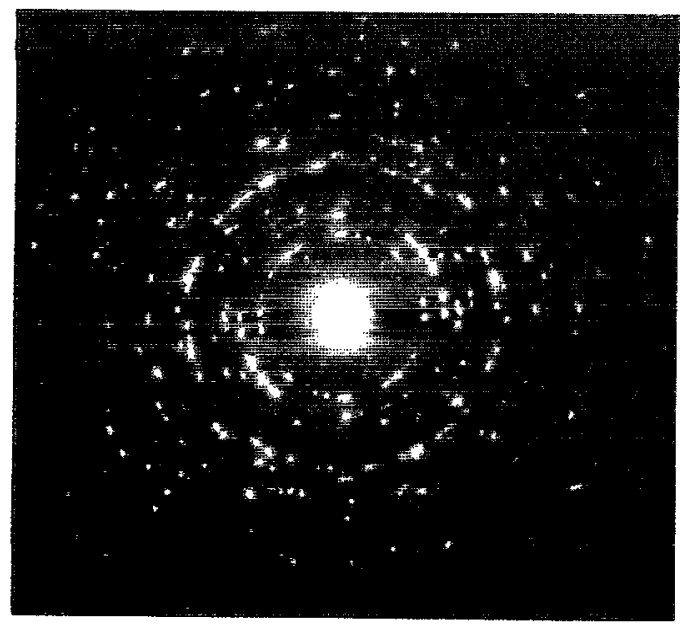

FIG. 3. Typical electron diffraction pattern of the $\mathrm{PZT} / \mathrm{RuO}_{2} / \mathrm{SiO}_{2} / \mathrm{Si}$ thin film.

Extensive arrays of $0.5 \mathrm{~nm}$ fringes may be seen in the $\mathrm{RuO}_{2}$ grains, indicating perhaps some preferred orientation. Further enlargement of the $\mathrm{RuO}_{2} / \mathrm{PZT}$ interface (Fig. 5) shows that this interface is not flat; it consists of a series of roughly periodic curved boundaries reflecting the shape of the outer surface of the columnar grains of $\mathrm{RuO}_{2}$. Figure 6 is a HRTEM image showing atomic resolution detail of two such curved segments. The PZT appears well crystallized; it is oriented with (100) lattice planes parallel to the original substrate in this case. Note that there is no evi-

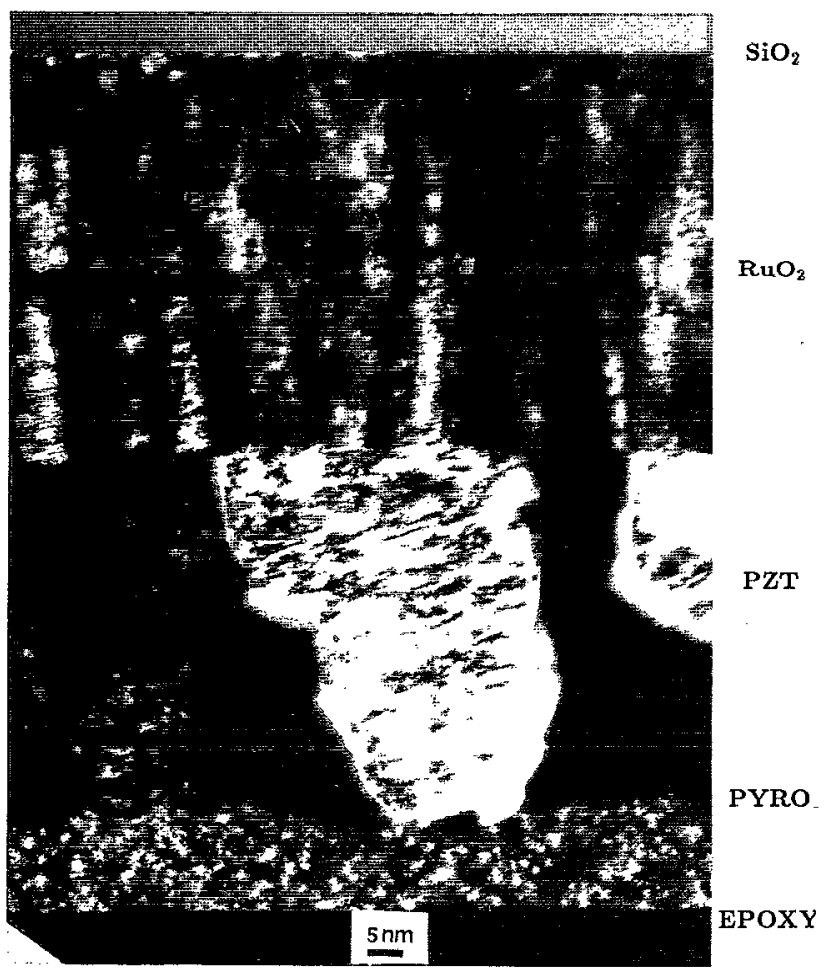

FIG. 4. Enlargement of Fig. 2 showing lattice fringes within the $\mathrm{RuO}_{2}$ grains. Note also the nanocrystalline pyrochlore layer.

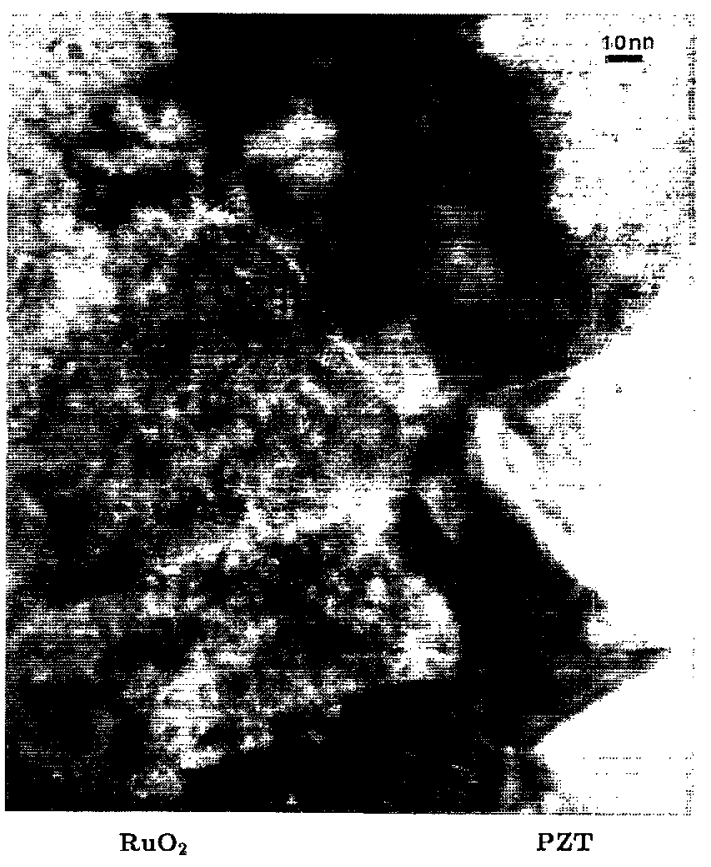

FIG. 5. $\mathrm{RuO}_{2} / \mathrm{PZT}$ interface showing curved interphase boundaries.

dence for an intermediate phase; in particular there is no pyrochlore-type phase at this part of the $\mathrm{RuO}_{2} / \mathrm{PZT}$ interface.

However, the PZT layer is incompletely crystallized as perovskite phase: a layer approx $50 \mathrm{~nm}$ thick has been stranded as a nanocrystalline structure; indicated by small bright contrast regions in the dark-field image (Figs. 2, 4) about 5-7.5 nm diam. The corresponding HRTEM image showed apparently randomly oriented nanocrystals consisting of 10-20 lattice fringe spacings. These lattice spacings were measured using an optical diffractometer, from which it was concluded that this was nanocrystalline pyrochlore. There was also some amorphous material at this outer surface. There were also some fluctuations in intensity with respect to background for this part of the PZT layer, which is consistent with loss of $\mathrm{PbO}$ by evaporation during the $650^{\circ} \mathrm{C}$ anneal.

HRTEM images of the $\mathrm{RuO}_{2} / \mathrm{SiO}_{2}$ interface showed that there were no problems with adhesion in this case; that interface was flat and continuous.

A $10 \mathrm{~nm}$ diam electron probe was used to obtain EDX spectra from a series of points tracing a line perpendicular to the series of interfaces; there was no evidence for interdiffusion of $\mathrm{RuO}_{2}$ into silica or of $\mathrm{RuO}_{2}$ into PZT, and the $\mathrm{Pb}: \mathrm{Zr}: \mathrm{Ti}$ ratio showed no systematic changes as a function of distance throughout the PZT layer, even up to the outer surface. This result implies that the cation stoichiometry of the pyrochlore phase is essentially $\mathrm{Pb}_{2} \mathrm{ZrTiO}_{7-x}(0<x$ $<1)$.

\section{B. PZT/Pt/Ti/SiO $/ 2 / \mathrm{Si}$}

A typical bright-field cross section is shown as Fig. 7. In this case only the Pt and PZT layers remain, since the $\mathrm{Si} / \mathrm{SiO}_{2} / \mathrm{Ti}$ layers were removed during specimen thinning 


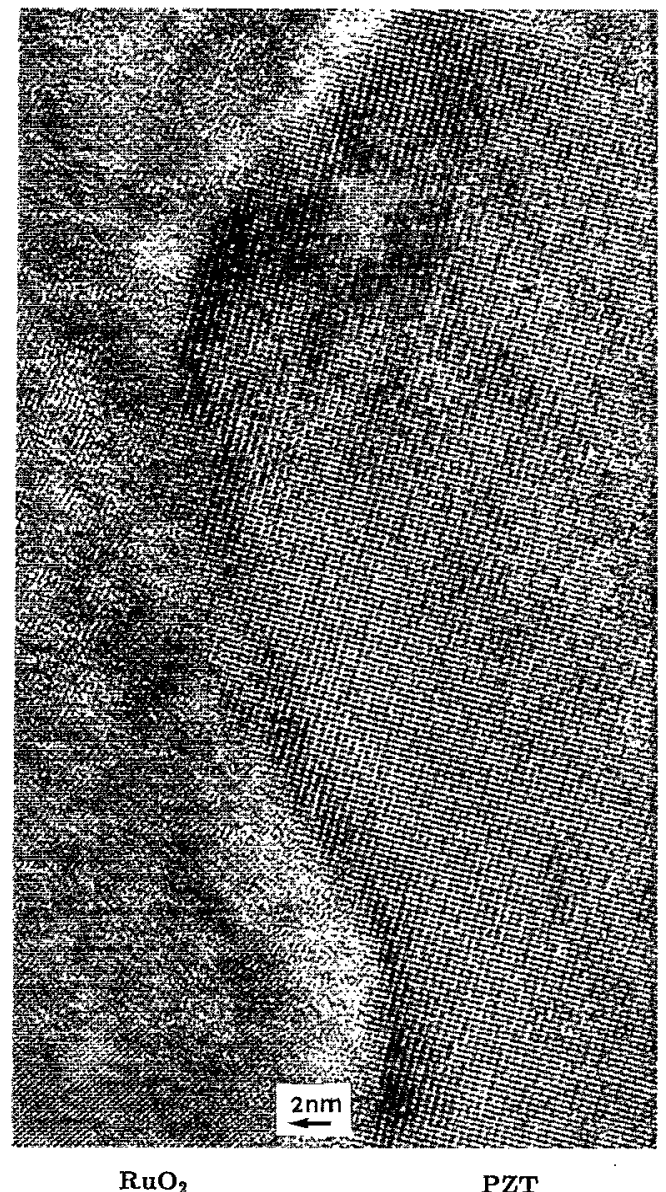

FIG. 6. HRTEM image of the $\mathrm{RuO}_{2} / \mathrm{PZT}$ interface showing [101] zone axis of PZT.

under ion bombardment. The PZT forms columnar grains extending from the $\mathrm{Pt} / \mathrm{PZT}$ interface to the outer surface, whereas the grains of $\mathbf{P t}$ are relatively much wider. Here again the PZT/electrode interface is broadened somewhat by the slight curvature of the grain boundaries; this effect is relatively small here compared to the case of $\mathrm{RuO}_{2} / \mathrm{PZT}$ just described. The original $\mathrm{Pt}$ surface was presumably relatively very flat compared to that of $\mathrm{RuO}_{2}$. The Pt/PZT interface was sharp, with no evidence for another phase separating the Pt and PZT layers. There are subgrain boundaries, i.e., dislocation arrays within the PZT. A HRTEM image from an area close to the outer surface of the PZT layer showed a few pockets of incompletely crystallized material, however, in general this PZT layer was a relatively very well crystallized perovskite structure throughout; certainly more so than was the case for the $\mathrm{PZT} / \mathrm{RuO}_{2}$ film described above.

\section{DISCUSSION}

\section{A. Comparison of the present results with Vijay and Desu (Ref. 1)}

An x-ray powder diffraction study of $\mathrm{PZT} / \mathrm{RuO}_{2} / \mathrm{SiO}_{2} / \mathrm{Si}$ thin films showed that the perovskite structure of PZT initiated at $550^{\circ} \mathrm{C}$ and was complete by

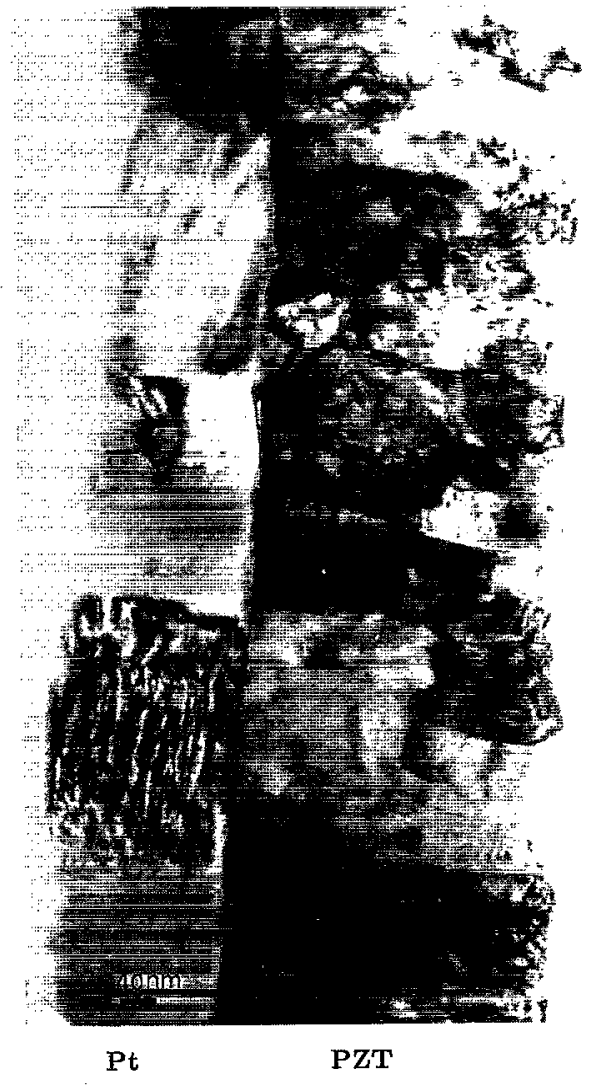

FIG. 7. Overview of the $\mathrm{PZT} / \mathrm{Pt} / \mathrm{Ti} / \mathrm{SiO}_{2} / \mathrm{Si}$ thin film showing the interface structures and the texture of the $\mathrm{Pt}$ and $\mathrm{PZT}$ layers.

$600{ }^{\circ} \mathrm{C}$. In addition to the $\mathrm{PZT}$ perovskite and $\mathrm{RuO}_{2}$ peaks, there were other peaks characteristic of a cubic pyrochlore phase $(a=1.06 \mathrm{~nm})$ : Vijay and Desu interpreted these as due to $\mathrm{Pb}_{2} \mathrm{Ru}_{2} \mathrm{O}_{7-x}$; asserting that this was consistent with Rutherford backscattering (RBS) depth profile results from the same films; which showed some diminution of $R u$ close to the PZT/ $\mathrm{RuO}_{2}$ interface. Our results showed no pyrochlore phase at the $\mathrm{PZT} / \mathrm{RuO}_{2}$ interface; rather nancrystallites of a pyrochlore phase appeared at the top surface of the PZT. This often happens with sol-gel thin films if there is insufficient excess $\mathbf{P b}$ added to the sol-gel precursor solution. ${ }^{10}$ It is also well known that a nanocrystalline pyrochlore phase occurs as an intermediate step during the crystallization of the PZT thin films (see, e.g., Ref. 11).

Note also that if the partial pressure of oxygen is too high or too low during annealing then the nonstoichiometric pyrochlore phase $\mathrm{Pb}_{2} \mathrm{ZrTiO}_{7-x} x \neq 1$, is stabilized; rather than stoichiometric $\mathrm{Pb}_{2}\left(\mathrm{Zr}_{x}, \mathrm{Ti}_{1-x}\right) \mathrm{O}_{6}$, as required for the perovskite structure. Experimental demonstration of this point was given in a recent paper by Bursill and Brooks. ${ }^{12}$ Perovskite is usually stoichiometric within very narrow limits for all components.

This interpretation for the nature of the pyrochlore phase found by $\mathrm{x}$-ray diffraction was confirmed by our HRTEM images (Fig. 6) and the EDX experiments, which showed no evidence for $\mathrm{Ru} / \mathrm{PZT}$ interdiffusion. No 
$\mathrm{Ru}$ was detected at all throughout the PZT film using EDX.

In order to explain the RBS results we note simply that the curvature of the grains forming the $\mathrm{PZT} / \mathrm{RuO}_{2}$ interface extends over approximately 5-6 nm normal to the original substrate. This was most clearly seen for Fig. 6, where the interface appears to have curved character with amplitude about $3 \mathrm{~nm}\left(10\right.$ times $d_{110}=0.28 \mathrm{~nm}$ ). This may be a pseudoperiodic minimal surface required to minimize elastic energy. Note that as this curved cusplike interface is eroded during a RBS experiment, starting from the PZT side, there will be an apparent diminution of $\mathrm{Ru}$ at the $\mathrm{PZT} / \mathrm{RuO}_{2}$ interface.

Our results do not absolutely rule out some chemical $\mathrm{Ru} / \mathrm{PZT}$ intermixing at the atomic level; e.g., the presence of a thin layer of $\mathrm{PbRuO}_{3}$ would be difficult to detect in the HRTEM image. Use of a nanoprobe (1 nm diam), rather than the $10 \mathrm{~nm}$ probe used for EDX analysis would provide more sensitivity.

\section{B. Comments concerning degradation mechanisms}

Unfortunately, the present experiments did not test the interfacial structures of both top and bottom electrodes, as required for capacitors and ferroelectric switching. It is our experience that the top electrodes are probably most critical for degradation properties; since after annealing, e.g., at $650^{\circ} \mathrm{C}$ for $30 \mathrm{~min}$ in the present case, there is some tendency to lose $\mathrm{PbO}$, leaving some void space. This effect is compounded by the tendency to retain some remanent pockets of pyrochlore phase, or even amorphous or poorly crystallized matcrial, close to the top surface of the PZT. Residual pyrochlore phase appears in most PZT thin films, more or less depending on the details of the annealing treatments (atmosphere, heating rate, time at temperature, etc.). Thus, the top surface of the PZT, and hence the top electrode/PZT interface is likely to be significantly less perfect than the bottom electrode/PZT interface.

There are also reports that producing the top Pt electrode by sputtering may introduce a damaged layer at the PZT/Pt interface, involving preferential desorption of oxygen. ${ }^{13}$ This has not yet been tested for $\mathrm{RuO}_{2} / \mathrm{PZT}$ electrodes; but a top electrode of $\mathrm{RuO}_{2}$, reactively sputtered in the presence of oxygen, is less likely to suffer this effect.

It is interesting that, for the present pair of films, the Pt/PZT was much better crystallized than was the $\mathrm{RuO}_{2} / \mathrm{PZT}$; only the latter showed pyrochlore. Nevertheless, the $\mathrm{RuO}_{2} / \mathrm{PZT}$ gave much better fatigue characteristics. It is not clear how the present results may be interpreted with respect to degradation properties. It appears necessary to examine films before and after fatigue experiments; to search for nanostructural changes which may be expected to occur if oxygen diffusion and trapping plays a significant role in degradation. So far, there have been no definitive studies on this point, although preliminary experiments showed no evidence for nanostructural changes at $\mathrm{Pt} / \mathrm{PZT}$ interfaces. ${ }^{14}$

\section{CONCLUSIONS}

It seems clear from the present experiments that useful thin film PZT can certainly be obtained using sol-gel methods combined with reactive sputtering of $\mathrm{RuO}_{2}$ electrodes; the PZT/electrode interfaces are chemically sharp and continuous. Care must be taken to minimize the presence of remanent pyrochlore phase; this can be managed, as shown by the present Pt/PZT film, although there were obvious problems with the outer surface of the $\mathrm{RuO}_{2} / \mathrm{PZT}$ film examined in the present work.

In searching for an explanation for the improved fatigue characteristics of $\mathrm{RuO}_{2}$ electrodes it seems that use of essentially close-packed conducting oxide electrodes, such as $\mathrm{RuO}_{2}$ or $\mathrm{SrRuO}_{3}$ may well significantly reduce oxygen diffusion and trapping at the PZT/electrode interfaces.

Finally, it must be admitted that the crystalline perfection of the PZT thin films is likely to become significant at some point; thus dislocations, point defects, and both neutral and charged small defect clusters may all interact with polar domain walls during switching and hence contribute to fatigue and other degradation phenomena. Probably, these (bulk) effects may only become evident when electrode/PZT interfaces have first been produced in a rather more controlled and reproducible manner than is generally the case at present.

\section{ACKNOWLEDGMENTS}

This work was supported financially by the Swiss National Funds for Research and the Australian Research Council. We are grateful for the enthusiastic support of Professor Nava Setter, Laboratoire de Ceramique, EPFL, and Dr. Pierre Stadelmann of Institut Interdepartementale de Microscopie Electronique, EPFL.

${ }^{1}$ D. P. Vijay and S. B. Desu (unpublished).

${ }^{2}$ I. K. Yoo and S. B. Desu, Phys. Status Solidi A 133, 565 (1992).

${ }^{3}$ I. K. Yoo and S. B. Desu, Proceedings of the International Symposium on Application Ferroelectrics (ISAF-92), edited by M. Liu, A. Safari, A. Kingon, and G. Haertling (IEEE, New York, 1992), p. 225.

${ }^{4}$ D. P. Vijay, C. K. Kwok, W. Pan, I. K. Yoo, and S. B. Desu, in Ref. 3, p. 408.

${ }^{5}$ S. B. Desu and I. K. Yoo, in Ref. 3, p. 412.

${ }^{6}$ L. D. Madsen and L. Weaver, J. Electron. Mater. 21, 93 (1992).

${ }^{7}$ I. Kondo, T. Yoneyama, and O. Takeuaka, J. Vac. Sci. Technol. A 10, 3436 (1992).

${ }^{8}$ I. M. Reancy and D. J. Barber, J. Microsc. 160, 213 (1990).

${ }^{9}$ K. Sreenivas, I. M. Reaney, T. Maeder, N. Setter, C. Jagadish, and R. G. Elliman, J. Appl. Phys. 75, 232 (1994).

${ }^{10}$ I. M. Reaney, K. G. Brooks, R. Klissourska, C. Pawlaczyk, and N. Setter, J. Amer. Ceram. Soc. (in press).

${ }^{11}$ C. K. Kwok and S. B. Desu, Appl. Phys. Lett. 60, 1430 (1992).

${ }^{12}$ L. A. Bursill and K. G. Brooks, J. Appl. Phys. (in press).

${ }^{13}$ G. R. Fox, Doctoral thesis, The Pennsylvania State University, 1992.

${ }^{14}$ I. M. Reaney et al. (unpublished results, 1992). 